\title{
HUBUNGAN STATUS GIZI DENGAN KEBUGARAN JASMANI SISWA-SISWI SMP NEGERI 1 AMBON
}

\author{
Mariana Ditboya Hukubun'1, Mieke Souisa² \\ 1,2 Dosen Prodi Pendidikan Jasmani Kesehatan dan Rekreasi FKIP Universitas Pattimura \\ Email: marianahukubun01@gmail.com¹, ms.souisa1512@gmail.com² \\ DOI: https://doi.org/10.36526/kejaora.v4i2.705
}

\begin{abstract}
ABSTRAK
Penelitian ini bertujuan untuk mengetahui hubungan status gizi dengan kebugaran jasmani siswasiswi SMP Negeri 1 Ambon. Penelitian ini merupakan jenis Penelitian deskriptif korelasional dan survei dengan menghubungkan variabel terikat dengan variabel bebas yaitu status gizi dengan tingkat kebugaran jasmani. Subjek dalam penelitian ini adalah siswa-siswi dengan berbagai status gizi yang berjumlah 28 orang. Berdasarkan uji hipotesis, maka hasil penelitian ini menunjukkan bahwa ada hubungan status gizi dengan kebugaran jasmani siswa-siswi SMP Negeri 1 Ambon, dengan nilai antara rx. $y=0.68$ dengan $r(0.05)(33)=0.30$. Karena koefisien korelasi antara rx1.y $=$ $0.68>r(0.05)(32)=0.30$, berarti koefisien korelasi tersebut signifikan. Bernilai positif artinya semakin baik status gizi seseorang maka akan semakin baik tingkat kebugaran jasmaninya. Gizi seseorang yang baik dan teratur memberikan dampak positif berkaitan dengan tingkat kebugaran jasmani.
\end{abstract}

Kata kunci: Status gizi, Keugaran Jasmani

\section{PENDAHULUAN}

Kebugaran jasmani berkaitan dengan kegiatan manusia dalam melakukan pekerjaan dan bergerak . Kebugaran jasmani yang dibutuhkan untuk mendukung aktivitas sehari-hari (pekerjaan) seseorang agar pekerjaan atau aktivitas tersebut optimal. Pekerjaan atau aktivias pun dapat mempengaruhi kebugaran jasmani seseorang. Salah satu cara untuk meningkatkan kebugaran tubuh adalah melalui olahraga yang dilakukan secara teratur, terukur, terprogram, sistematis dan selalu meningkat. Pembinaan kondisi fisik melalui olahraga merupakan pondasi untuk meningkatkan kebugaran jasmani, sehingga dapat beraktivitas dengan baik. Seseorang yang memiliki kebugaran jasmani yang baik akan terhindar dari kemungkinan cedera pada saat melakukan aktivitas fisik atau olahraga yang lebih berat.

Keberhasilan mencapai tingkat kebugaran jasmani yang baik menurut Djoko Pekik Irianto (2004: 16-21) sangat ditentukan oleh kualitas latihan yang dijabarkan dalam konsep FIT (Frekuensi, Intensiti, Time). (1) Frekuensi latihan untuk meningkatkan kebugaran jasmani perlu dilakukan 3-5 kali per minggu. Waktu yang digunakan untuk berlatih dilakukan 20-60 menit. Baiknya dilakukan berselang misal: senin, rabu, jumat, sedangkan hari yang lain digunakan untuk istirahat agar tubuh memiliki kesempatan melakukan rekovery (pemulihan) tenaga, (2) Intensitas kualitas yang menunjuk berat ringannya latihan. Besarnya intensitas tergantung pada jenis dan tujuan latihan. Secara umum intensitas latihan kebugaran adalah $60 \%$ - 90\% detak jantung maksimal dan secara khusus besarnya intensitas latihan bergantung pada pada tujuaan latihan, (1) Time adalah waktu atau durasi yang diperlukan setiap kali berlatih. Untuk meningkatkan kebugaran paru-jantung dan penurunan berat badan diperlukan waktu berlatih 20-60 menit.

Kebugaran jasman bersasal dari istilah physical fitness, secara harfiah physical fitness kecocokan atau kesesuayan fisik /jasmani , yang di maksut dengan cocok ialah tugas fisik yang harus dilaksanakan untuk dapat melaksanakan tugas fisik itu di perlukan syarat syarat fisik/jasmani tertentu

Syarat-syarat tersebut dapat bersifat anatomis (struktural) atau fisiologis (fungsional) anatomi fitness bersangkutan dengan syarat-syarat yang berhubungan 
dengan ukuran-ukuran dan dan ketrampilan fisik yaitu :

1. tinggi badan

2. berat badan

3. kelengkapan angota badan

Pisiological fitness besankutan dengan syarat-syara fisik yang berupa kemampuan menyesuaikan fungsi yang fisiologis dari alat-alat tubuhnya terhadap keadaan lingkungan (suhu, kelembapan, ketinggian) dan atau fisik yang berupa kerja otot secara efisien, tidak lelah secara berlebihan, sesehingga masih mampu melakukan kegiatan-kegiatan yang bersifat rekretif di luar waktu kerja dan telah mengalami pemulihan yang sempurna sebelum datang tugas yang sama esok harinya. jadi physical fitness ialah keampuan tubuh untuk berfungsi dengan baik sesuai dengan beratnya tugas yang harrus dilaksanakannya

Pentingnya kebugaran jasmani bagi anak usia sekolah antara lain dapat meningkatkan kemampua organ tubuh, sosial emosional, sportifitas dan semangat kompetetisi beberapa peneliti juga menyebutkan bahwa kebugakran jasmani memiliki koorelasi positif dengan prestasi akademis. dari sudut pandang pendidikan upaya peningkatan kesegaraan jasmani memeliki tujuan antar lain :

1) Pembentukan gerak

2) Pembentukan prestasi

3) Pembentukan sosial

4) Pertumbuhan badan

Untuk memperoleh kebugaran jasmani yang baik maka, dibutuhkan latihan fisik dengan frekuensi latihan yang teratur. Akan tetapi realisasinya setiap orang yang memiliki tingkat kebugaran jasmani yang berbeda karena kegiatan pola asupan gisi dan waktu istiarahat yang dilakukan setiap orang pun berbeda karena kebugaran jasmani terdiri dari bermacam - macam unsur, seperti dikemukakan oleh Sudarno (1991:2122) bahwa unsur kebugaran jasmani terdiri dari : kesehatan yang baik, kekuatan, kelincahan, ketahanan muskular, kecepatan, keseimbangan, kelentukan, kooedinasi, ketahanan kardiorespirasi, berat badan yang sesuai, kemampuan motorik umum, dan ketangkasan neurom muskular.
Selain itu untuk mendapatkan hasil kebugaran yang baik status gizi sangat berpengaruh. Menurut Marsetyo(2008) menyatakan bahwa perkembangan tubuh manusia dapat melakukan kegiatan fisiknya sehari-hari, maka tubuh manusia harus dipenuhi kebutuhan zat-zat makanan/zat-zat gizinya. Kadar zat makanan (gizi) pada setiap makanan memang tidak sama,

Menurut Sunita Almatsier (2003), secara klasikal zat gizi hanya dihubungkan dengan kesehatan tubuh, yaitu untuk menyediakan energy, membangun dan memelihara jaringan tubuh, serta mengatur proses-proses kehidupan dalam tubuh .

Status gizi merupakan gambaran tentang keseimbangan tubuh akan kebutuhan zat makanan yang dikonsumsi tubuh. Dan dapat diperoleh melalui proses yang berkenan dengan pemeliharaan dan perbaikan organ-organ tubuh. Menurut I Dewa Nyoman Supriasa (2002) status gizi adalah ekspresi dari keadaan keseimbangan dalam bentuk variable tertentu atau perwujudan dari nutrient dalam bentuk variable tertentu.

Selain itu status gizi adalah keadaan tubuh yang diakibatkan oleh konsumsi, penyerapan dan penggunaan makanan. Susunan makanan yang memenuhi kebutuhan gizi, pada umumnya dapat menciptakan gizi yang memuaskan.

Status gizi sebagai suatu keadaan tingkat pemenuhan status gizi seseorang, yang diperoleh oleh asupan makanan seharihari, baik yang berasal dari tumbuhan maupun berasal dari hewan yang berkaitan erat dengan kebugaran jasmani..

Sebagai sumber strategi tubuh terutama menggunakan lemak dan karbohidrat, adapun vitamin merupakan bahan pengatur walaupun masih ada anggapan bahwa vitamin merupakan sumber tenaga. Demikian halnya dengan mineral fungsi utama adalah sebagai bahan pengatur, namun kadang-kadang berfungsi juga sebagai pembangun, misalnya kalsium untuk membangun tulang dan gigi. Padahalnya kalsium juga diperlukan sebagai kontraksi otot.

Berkaitan dengan status gizi yang didalamnya meliputi pemenuhan kebutuhan gizi makanan dengan kemapuan 
melaksanakan tugas sehari-harinya yang memerlukan adamya kesegaran jasmani, maka dapat dikatakan bahwa status gizi sangat erat hubunganya dengan kebugaran jasmani. Berkaita dengan hal tersebut, relevansi yang sangat tampak dari nilai kecukupan gizi bagi tubuh, maka berdasarkan dengan kegunaan yang dapat diperoleh dari zat-zat gizi makanan adalah untuk memenuhi zat gizi bagi tubuh, yaitu sebagai sumber energi, bahan pembangun dan bahan pengatur (Rasyid M.Tauhid, 1986:44). Karena untuk dapat melakukan tugas sehari-hari dengan baik diperlukan adanya energi sebagai penggerak.dengan demikian dapat dikatakan bahwa untuk mendapatkan kesegara jasmani diperlukan gizi, sebaliknya keberadaan gizi mampu meningkatkan kebugaran jasmani.

Dengan demikian status gizi sesorang sangat berpengaruh terhadap tingkat kebugaran seseorang. Jika gizinya seimbang maka kebugarannya pun akan lebih baik.

\section{METODE}

Penelitian ini merupakan jenis Penelitian deskriptif korelasional dan survei dengan menghubungkan variabel terikat dengan variabel bebas yaitu pengambilan data dilakukan dalam satu waktu dengan tujuan untuk mengetahui hubungan antar variable status gizi dengan kebugaran jasmani siswa SMP Negeri 1 Ambon.

Teknik pengambilan sampel dalam penelitian ini adalah purposive sampling . Dengan krieteria yang telah dipilih oleh peneliti. Sesuai dengan status gizi yang telah di ukur sesuai dengan IBM pada tiap-tiap orang.

\section{HASIL}

Subjek penelitian adalah siswasiswa SMP Negeri 1 Ambon yang berjumlah 28 orang. Dalam penelitian ini data yang dimaksud adalah data yang diperoleh menggunakan teknik pengumpulan data dengan tes dan pengukuran. Data dalam penelitian ini terdiri atas; (1) status gizi yang diukur menggunakan timbangan dan meteran dan dihitung dengan IBM, (2) kebugaran jasmani.

Penelitian ini bertujuan untuk mengetahui ada tidaknya hubungan antara status gizi dengan kebugaran jasmani siswasiswi SMP Negeri 1 Ambon. Hasil rangkuman data penelitian sebagai berikut:

\begin{tabular}{ccc}
\multicolumn{3}{c}{ Tabel 1. Rangkuman Hasil Penelitian } \\
\hline No & Status Gizi & Kebugaran Jasmani \\
\hline $\mathbf{1}$ & 16 & 17 \\
\hline $\mathbf{2}$ & 13 & 17 \\
\hline $\mathbf{3}$ & 13 & 19 \\
\hline $\mathbf{5}$ & 16 & 14 \\
\hline $\mathbf{6}$ & 11 & 19 \\
\hline $\mathbf{7}$ & 17 & 17 \\
\hline $\mathbf{8}$ & 14 & 13 \\
\hline $\mathbf{9}$ & 13 & 18 \\
\hline $\mathbf{1 0}$ & 18 & 12 \\
\hline $\mathbf{1 1}$ & 12 & 17 \\
\hline $\mathbf{1 2}$ & 11 & 18 \\
\hline $\mathbf{1 3}$ & 13 & 12 \\
\hline 14 & 9 & 15 \\
\hline $\mathbf{1 5}$ & 12 & 19 \\
\hline $\mathbf{1 6}$ & 17 & 15 \\
\hline $\mathbf{1 7}$ & 12 & 15 \\
\hline 14 & 14 & \\
\hline & & 17 \\
\hline
\end{tabular}




\begin{tabular}{lll}
\hline $\mathbf{1 8}$ & 11 & 15 \\
\hline $\mathbf{1 9}$ & 9 & 13 \\
\hline $\mathbf{2 0}$ & 15 & 18 \\
\hline $\mathbf{2 1}$ & 11 & 14 \\
\hline $\mathbf{2 2}$ & 11 & 17 \\
\hline $\mathbf{2 3}$ & 14 & 20 \\
\hline $\mathbf{2 4}$ & 10 & 14 \\
\hline $\mathbf{2 5}$ & 14 & 17 \\
\hline $\mathbf{2 6}$ & 14 & 17 \\
\hline $\mathbf{2 7}$ & 15 & 14 \\
\hline $\mathbf{2 8}$ & 14 & 15
\end{tabular}

\section{Status Gizi}

Hasil penghitungan data status gizi siswa-siswi SMP Negeri 1 Ambon menghasilkan rerata sebesar 13,17 dan standar deviasi sebesar 2,37 Nilai terkecil sebesar 9 dan terbesar sebesar 18. Tabel distribusi data status gizi adalah sebagai berikut:

Tabel 2. Distribusi Frekuensi Panjang Tungkai

\begin{tabular}{cccc}
\hline NO. & $\begin{array}{c}\text { Kelas } \\
\text { Interval }\end{array}$ & $\begin{array}{c}\text { Frekuensi } \\
\text { Absolut }\end{array}$ & $\begin{array}{c}\text { Frekuensi } \\
\text { Relatif }\end{array}$ \\
\hline $\mathbf{1}$ & $9-10$ & 3 & 11 \\
\hline $\mathbf{2}$ & $11-12$ & 8 & 29 \\
\hline $\mathbf{3}$ & $13-14$ & 10 & 36 \\
\hline $\mathbf{4}$ & $15-16$ & 4 & 14 \\
\hline $\mathbf{5}$ & $17-18$ & 3 & 11 \\
\hline & Jumlah & 28 & 100 \\
\hline
\end{tabular}

Berdasarkan tabel di atas terlihat bahwa sebagian besar besar status gizi siswa-siswi SMP Negeri 1 Ambon berada pada interval $13-14$ dengan persentase sebesar $10 \%$. Apabila ditampilkan dalam bentuk histogram, maka data status gizi tampak pada gambar sebagai berikut:

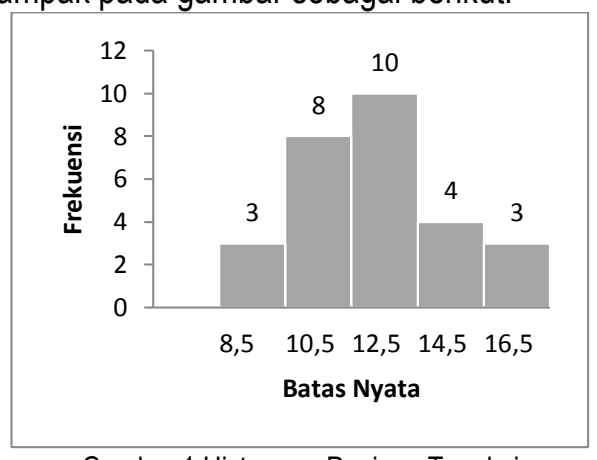

Gambar 1 Histogram Panjang Tungkai

\section{Kebugaran Jasmani}

Hasil penghitungan data kebugaran jasmani siswa-siswi SMP Negeri 1 Ambon menghasilkan rerata sebesar 16 dan standar deviasi sebesar 2,23 Nilai terkecil sebesar 12 dan terbesar sebesar 20. Tabel distribusi data kebugaran jasmani adalah sebagai berikut:

Tabel 3. Distribusi Frekuensi Panjang Lengan

\begin{tabular}{cccc}
\hline NO. & Kelas Interval & $\begin{array}{l}\text { Frekuensi } \\
\text { Absolut }\end{array}$ & $\begin{array}{l}\text { Frekuensi } \\
\text { Relatif }\end{array}$ \\
\hline $\mathbf{1}$ & $12-13$ & 4 & 14 \\
\hline $\mathbf{2}$ & $14-15$ & 9 & 32 \\
\hline $\mathbf{3}$ & $16-17$ & 8 & 29 \\
\hline $\mathbf{4}$ & $18-20$ & 7 & 25 \\
\hline & Jumlah & 28 & 100
\end{tabular}

Berdasarkan tabel di atas terlihat bahwa sebagian besar kebugaran jasmani siswa-siswi SMP Negeri 1 Ambon berada pada interval 14-15 dengan persentase sebesar $32 \%$. Apabila ditampilkan dalam bentuk histogram, maka data kebugaran jasmani tampak pada gambar sebagai berikut:

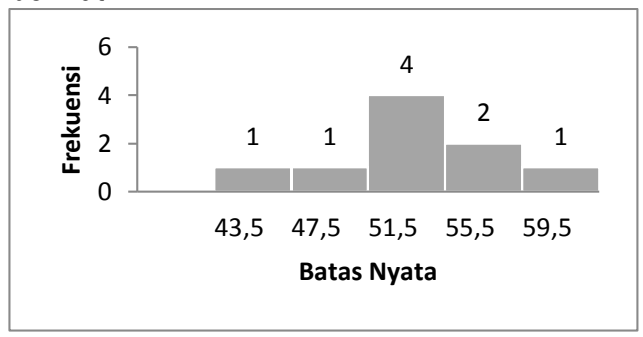

Gambar 2 Histogram Kebugaran Jasmani

\section{Hasil Analisis Data}

\section{Uji Hipotesis}

Analisis data penelitian yang digunakan untuk menguji hipotesis terdiri atas 
analisis korelasi sederhana. Untuk memperjelas hubungan antara variabel bebas dengan variabel terikat.

\section{a. Hubungan Antara Status Gizi Dengan Kebugaran Jasmani siswa-siswi SMP Negeri 1 Ambon}

Uji hipotesis berbunyi " Terdapat hubungan yang signifikan antara status gizi dengan kebugaran jasmani siswa-siswi SMP Negeri 1 Ambon".

Hasil uji hipotesis dengan menggunakan analisis regresi korelasi dapat dilihat pada tabel berikut ini.

Tabel 4. Koefisien Korelasi antara status gizi $(\mathrm{X})$
dengan Kemampuan
\begin{tabular}{clll}
\hline Korelasi & $\mathbf{r}$ hitung & $\mathbf{r}$ tabel & Keterangan \\
\hline $\mathbf{X . Y}$ & 0.68 & 0.30 & Signifikan \\
\hline
\end{tabular}

Berdasarkan hasil analisis tersebut di atas diperoleh koefisien korelasi status gizi dengan kebugaran jasmani sebesar 0.68 yang bernilai positif, artinya semakin besar nilai yang mempengaruhi maka semakin besar nilai hasilnya. Uji keberartian koefisien korelasi tersebut dilakukan dengan cara mengonsultasi harga rx.y $=0.68$ dengan $r(0.05)(28)=0.30$. Karena koefisien korelasi antara rx.y $=0.68>r(0.05)(27)=0.30$, berarti koefisien korelasi tersebut signifikan. Dengan demikian hipotesis yang berbunyi "Ada hubungan yang signifikan antara status gizi dengan kebugaran jasmani siswa-siswi SMP Negeri 1 Ambon", diterima. Artinya terdapat hubungan yang signifikan antara status gizi dengan kebugaran jasmani siswa-siswi SMP Negeri 1 Ambon.

\section{PEMBAHASAN}

Penelitian ini bertujuan untuk mengetahui hubungan yang signifikan antara status gizi dengan kebugaran jasmani siswa-siswi SMP Negeri 1 Ambon.Hasil analisis menunjukkan bahwa ada hubungan status gizi dengan kebugaran jasmani siswasiswi SMP Negeri 1 Ambon, dengan nilai antara rx.y $=0.68$ dengan $r(0.05)(33)=0.30$. Karena koefisien korelasi antara rx1.y $=0.68$ $>r(0.05)(32)=0.30$, berarti koefisien korelasi tersebut signifikan. Bernilai positif artinya semakin baik status gizi seseorang maka akan semakin baik tingkat kebugaran jasmaninya. Gizi seseorang yang baik dan teratur memberikan dampak positif berkaitan dengan tingkat kebugaran jasmani.

\section{KESIMPULAN}

Penelitian ini menggunakan metode korelasional yang menguji hubungan antar dua variable. Berdasarkan data yang diperoleh dari hasil analisis dan pengujian hipotesis penelitian maka dapat disimpulkan siswa yang mempunyai status gizi yang baik akan mempengaruhi tingkat kebugaran jasmaninya. Dengan kata lain status gizi sangat mempengaruhi tingkat kebugaran jasmani seseorang.

\section{DAFTAR PUSTAKA}

Adi, B. (2010). Meningkatkan Kebugaran Jasmani Anak SD Melalui Latihan Kebugaran Aerobic. Dosen jurusan FIP UNY.

Almatsier, Sunita (2003). Prinsip Dasar IImu Gizi. Jakarta: Pustaka Utama.

Arikunto, S. (2010). Prosedur Penelitian Suatu Pendekatan Praktk. Jakarta: PT. Rineka Cipta.

Baliwati, Y, F. (2004). Pengantar Pangan Gizi. Cetakan I. Jakarta: Suadaya.

Depdikbud. (1998). Tes Kebugaran Jasmani Indonesia. Jakarta.

Hermani, R, A. Mansyur, M. (2013). Peran Indeks Masa Tubuh, Tanda Vital dan Sosiodemografi Terhadap Kebugaran Peserta Klub Jantung Sehat Jakarta Timur. e-jurnal Kedokteran Indonesia 1(3).

Irianto, Djoko, Pekik. (2006). Panduan Gizi Lengkap Keluarga dan Olahragawan. Yogyakarta.

Karta Sapoetra, Marsetyo. (2003) Korelasi Gizi Kesehatan dan Produktifitas Kerja. Jakarta: PT. Gramedia Pustaka Utama.

Muhajir. (2007). Pendidikan Jasmani Olahraga dan Kesehatan. Jakarta: Erlangga.

Supariasa. (2002). Penilaian Status Gizi. Jakarta: EGC. 